\title{
8. CONTRASTING MAGNETIC PROPERTIES IN LEG 107 SEDIMENTS: PRESERVATION AND ALTERATION OF TITANOMAGNETITE AT ADJACENT SITES 1
}

\author{
J.E.T. Channell, ${ }^{2}$ T. Hawthorne, ${ }^{2}$ and M. Torii ${ }^{3}$
}

\begin{abstract}
Primary magnetization components in Plio-Pleistocene sediments at Sites 650, 651, 652, and 654 are carried by titanomagnetite, and can be resolved by progressive thermal demagnetization. Messinian balatino-type gypsum and the underlying Tortonian sediments at Site 654 and the pre-Pliocene sediments at Site 652 also appear to carry a primary magnetization.

In contrast, at Hole $653 \mathrm{~A}$, the detrital titanomagnetite has been partially altered by reducing diagenetic conditions in the Plio-Pleistocene sediments. Demagnetization techniques resolved secondary and composite magnetization components which usually have steep downward inclinations. Natural remanent magnetization (NRM), saturation isothermal magnetization (SIRM) intensity, and susceptibility tend to decrease downcore, whereas the coercivity of the NRM increases downcore. Microscopic (SEM) observation of pitted titanomagnetites coated by secondary iron sulfide, and an increase in the ratio of ferrous/ferric iron downcore, indicate that the changes in magnetic properties can be explained by progressive reduction of detrital titanomagnetite to iron sulfide.
\end{abstract}

\section{INTRODUCTION}

The standard chronostratigraphic units of the late Neogene were introduced with reference to marine land sections in Italy, where the stratotype sections are located. Correlation of paleontological events from the Mediterranean Neogene to the open ocean is therefore critical to global Neogene stratigraphy, and has not been satisfactorily accomplished. Magnetostratigraphy in the Mediterranean Neogene is the key to achieving this correlation. Leg 107 afforded the opportunity to acquire the required magnetostratigraphy. The stratigraphic objectives of Leg 107 were focused on Site 653 (Fig. 1), and this was the only site cored using the double APC technique. Although the other Leg 107 sites yielded primary magnetization components, the magnetic properties at Site 653 were such that a primary magnetization could not be resolved. This paper attempts to provide an explanation for the contrasting magnetic properties observed at closely adjacent Leg 107 drilling sites.

At Sites 651,652 , and 654 (Fig. 1), the quality of the magnetostratigraphic and biostratigraphic record is severely limited by poor recovery and core disturbance associated with rotary drilling. Site 650 was drilled using the APC/XCB technique and the physical quality of the core was improved. However, the oldest sediment at this site was uppermost Pliocene in age. In spite of the poor physical quality of the cores at Sites 652 and 654, the magnetostratigraphies are such that most polarity chrons down to Chron 7 (Chron 4 in the nomenclature of Cox, 1982) can be correlated to the biostratigraphy (Channell et al., this volume). The purposes of this paper are (1) to review the magnetic properties of Leg 107 sediments with particular attention to the differences in magnetic properties of the Plio-Pleistocene sediments which account for the absence of a clear magnetostratigraphic record at Hole $653 \mathrm{~A}$, but relatively pristine records at Sites $650,651,652$, and 654 ; (2) to give an account of the magnetic properties of the Miocene sediments recovered at Site 652 and Site 654, with special reference to the Messinian balatino-

\footnotetext{
${ }^{1}$ Kastens, K. A., Mascle, J., et al., 1990. Sci. Results, Proc. ODP, 107: College Station, TX (Ocean Drilling Program)

2 Department of Geology, University of Florida, Gainesville, FL 32611

${ }^{3}$ Department of Geology and Mineralogy, Kyoto University, Kyoto 606, Japan.
}

type gypsum recovered at Site 654 which appears to carry a primary magnetization.

\section{METHODS \\ Magnetic Methods}

The shipboard cryogenic magnetometer has the capability to measure magnetic remanence in whole cores or archive halves of core sections. The magnetometer system incorporates an on-line alternating field demagnetizer which can be used to subject the core to peak alternating fields of up to a maximum of $8 \mathrm{mT}$. The ODP regulations dictated the maximum peak field and mandated that alternating field demagnetization be used only on the archive halves, and not on the whole cores. The cryogenic magnetometer system could not be used to resolve the magnetostratigraphies from Leg 107 cores for several reasons. The magnetometer electronics were being modified during the previous Leg and failed to reach the ship until midway through the cruise. Hence the system was not used at the first three sites. At Sites 653 and 654 (as well as 652$)$, the peak allowable alternating field $(8 \mathrm{mT})$ was insufficient to resolve a well-defined magnetization component. In addition, the poor physical quality of the core at Sites 652 and 654 necessitated selective subsampling to avoid disturbed intervals. The magnetostratigraphies from Leg 107 are based entirely on subsamples taken by inserting $7-\mathrm{cm}^{3}$ plastic cubes into the sediment. The more indurated Miocene sediments were sampled by sawing oriented cubes from the working splits of the cores.

Alternating field demagnetization of subsamples up to maximum peak fields of 20 to $30 \mathrm{mT}$ was the basis for the magnetostratigraphy resolved on board ship. Subsequently, shorebased thermal demagnetization was used to resolve a high blocking temperature component. At each site, the published magnetostratigraphy is based on the high blocking temperature component directions (Channell et al., this volume). The thermal demagnetization technique involved allowing the sediment in the plastic cubes to dry in field-free space. Shrinkage of the sediment facilitates removal of the sediment from the plastic cube. The sediment cube is then wrapped in aluminum foil and the orientation and identification marks transposed. Progressive thermal demagnetization was then carried out until the remanence intensity fell close to the noise level of the cryogenic magnetometer.

When it was realized that thermal demagnetization at Site 653 was not resolving a magnetostratigraphy, other magnetic methods were used to investigate the magnetic mineralogy at this site. Further alternating field demagnetization was used to determine the variation of median destructive field (MDF) downcore. Acquisition curves of isothermal remanent magnetization (IRM) provided additional methods for evaluating the coercivity spectrum (Dunlop, 1972). The downcore variations in in- 


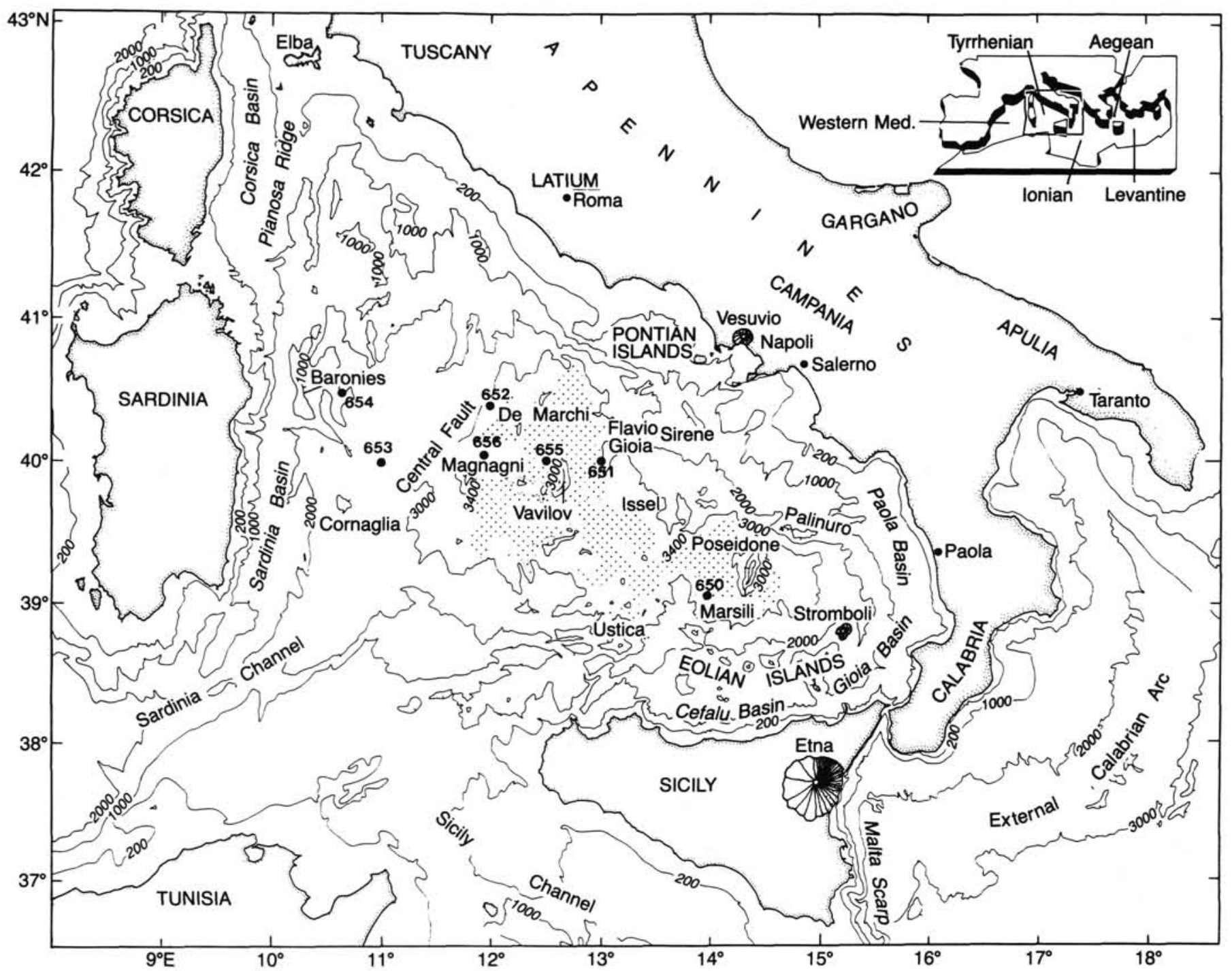

Figure 1. Location of Sites $650,651,652,653$, and 654 in the Tyrrhenian Sea.

tensity of SIRM, NRM, and anhysteretic magnetization (ARM) provided information on changes in magnetic mineralogy with depth (King et al., 1982; Bloemendal et al., 1988; Doh et al., 1988). The ARM was acquired in a biasing d.c. field of $0.05 \mathrm{mT}$ with a peak alternating field of $100 \mathrm{mT}$, and the SIRM in a magnetizing field of $0.9 \mathrm{~T}$. The contrast between the responses to AF demagnetization of the NRM, the ARM, and the SIRM can give an indication of the domain state of magnetite (Lowrie and Fuller, 1971; Johnson et al., 1975).

\section{Magnetic Extraction and Microscopy}

The extraction procedure described below has been tested on a variety of magnetite-bearing sediments. It is capable of extracting submicrometer-sized magnetite grains, and does not appear to be grain-size selective. For this study, $50 \mathrm{~g}$ of sample from Core 3 and the same weight of sample from Core 13 (both from Hole 653A) were added to flasks containing $650 \mathrm{~mL}$ of acetic acid buffered to a pH of 5.0. No carbonate remained after 2.5 days. In order to determine whether any ferrous iron had been digested by the solution, approximately $10 \mathrm{mg}$ of bathophenanthroline was added to $3 \mathrm{~mL}$ of the solution. As the solution did not become orange in color, it was concluded that no detectable ferrous iron had been assimilated by the solution. After dissolution of the carbonate, $100 \mathrm{~mL}$ of a $4 \%$ solution of sodium hexametaphosphate was added to disperse the clays. The solution was then agitated in an ultrasonicator for $10 \mathrm{~min}$. This solution was introduced into the extraction line, the purpose of which is to allow the solution to pass, at a very slow flow rate, close to a rare earth magnet. The magnet is placed on top of a re- movable section of tube, oriented at approximately $45^{\circ}$. After the solution has passed the magnet, the extraction line was flushed with deionized water in order to remove the nonmagnetic particles adhering to the removable tube. The magnet and the tube were then removed from the extraction line and the magnetic extract flushed out of the tube. Several drops of suspended extract was placed on an aluminum stub, dried, and sputter coated with gold for scanning electron microscopy. Images were obtained from both back scattered and secondary electrons. Elemental determinations were made with an energy dispersive $\mathrm{X}$-ray fluorescence unit (EDS).

\section{Ferrous/Ferric Iron Ratio}

The ferrous iron content of samples was determined using the spectrophotometric technique described by Fritz and Popp (1985). In order to determine the ferrous/ferric iron ratio, the total iron was determined using inductive plasma coupling (IPC) techniques.

\section{RESULTS: PRIMARY MAGNETIZATIONS AT SITES 650, 651, 652, AND 654}

\section{Plio-Pleistocene Sediments}

The shipboard alternating field demagnetization of PlioPleistocene sediments at Sites $650,651,652$, and 654 resolved initial magnetostratigraphies. However, subsequent shore-based thermal demagnetization was able to resolve a high blocking 
temperature component (Fig. 2), which improved the quality of the magnetostratigraphies. Distinct magnetization components were often present (see 10-1, 59 and 21-1, 24 in Fig. 2). The maximum blocking temperatures were always below $600^{\circ} \mathrm{C}$, with significant decreases in magnetization intensities in the $500^{\circ}-$ $600^{\circ} \mathrm{C}$ temperature range.

\section{Messinian Evaporites at Site 654}

The balatino-type gypsum recovered at Site 654 has weak NRM intensities (average $\mathrm{Jr} \approx 10^{-3} \mathrm{~A} / \mathrm{m}$ ), but alternating field demagnetization usually reveals a single magnetization component (Fig. 3). This component is not always well defined due to the low NRM intensities which are often close to magnetometer noise level. However, this magnetization component always has negative (upward) inclination, and the values are close to that expected for the site location. We interpret this magnetization component as being primary, and use it to place tight time constraints on deposition of the upper evaporite.

The NRM of the balatino-type gypsum has moderate coercivity. Median destructive fields range between 30 and $50 \mathrm{mT}$. The coercivity of the NRM is greater than the coercivity of the SIRM but lower than the coercivity of the ARM (Fig. 4). The IRM acquisition curves indicate that saturation usually occurs in the range between $0.1 \mathrm{~T}$ and $0.3 \mathrm{~T}$ (Fig. 5). These data are consistent with fine-grained (single domain) magnetite as the remanence carrier in the balatino-type gypsum. We suggest that the magnetite is associated with the thin (few millimeters thick) marly laminae between the whiter gypsum-rich layers. The isolation of a stable primary magnetization component in these gypsum beds allows their deposition to be placed in a precise time-frame.

\section{Tortonian Marls at Site $\mathbf{6 5 4}$}

Magnetostratigraphy in the Tortonian marls was based on the high blocking temperature component resolved by thermal demagnetization (Fig. 6). Maximum blocking temperatures were below $575^{\circ} \mathrm{C}$, with often a significant drop in magnetization intensity between 500 and $550^{\circ} \mathrm{C}$.

\section{Pre-Pliocene (Messinian?) Mudstones at Site 652}

Over $500 \mathrm{~m}$ of pre-Pliocene sediments were recovered at Site 652 . With the exception of a few samples, the sequence is characterized by high blocking temperature components with negative inclination (Fig. 7). The maximum blocking temperatures are generally below $575^{\circ} \mathrm{C}$. The reversed magnetization of this sequence led to the interpretation that the entire sequence was deposited during the lowest reversed interval of the Gilbert Chron.

\section{RESULTS: ALTERATION OF TITANOMAGNETITE AT SITE 653}

\section{Magnetic Properties-Observations}

As Site 653 was earmarked as the principal site with stratigraphic objectives, a great deal of effort was made to resolve a magnetostratigraphy from the Plio-Pleistocene sediments. Shipboard alternating field demagnetization was unsuccessful at defining a magnetostratigraphy and therefore extensive thermal demagnetization was conducted on shore. Orthogonal projections of thermal demagnetization data revealed the presence of a high blocking temperature component (Fig. 8), but the inclination of this component was generally steep and downward, and did not define a magnetostratigraphy (Fig. 9).

There are several magnetic parameters measured at Site 653 which indicate a change in magnetic properties downcore. Shipboard whole-core susceptibility measurements show variable values in the top $50 \mathrm{~m}$, with a decreasing trend down to about
100 mbsf (Fig. 10). This could be explained in terms of variations in detrital input through time, or downcore diagenetic change affecting the magnetic mineralogy. A similar trend is seen in the NRM intensities (Fig. 11), SIRM intensities (Fig. 12), and ARM intensities (Fig. 13). An increasing trend is seen in the variation of median destructive field with depth (Fig. 14). The increase continues below 100 mbsf.

IRM acquisition curves from samples down to $100 \mathrm{mbsf}$ at Site 653 (Fig. 15) indicate saturation in low magnetizing fields, and therefore the absence of high coercivity minerals. However, both the MDF/depth plot (Fig. 14) and the alternating field demagnetization of the NRM of individual samples (open squares in Fig. 16) indicate that there is a tendency for the NRM to harden downcore. In addition, the response of ARM and SIRM to alternating field demagnetization appears to change downcore (Fig. 16). Below Core 7, the ARM appears to get softer relative to the SIRM.

Susceptibility variations during heating are a sensitive indicator for the presence of iron sulfides, which alter to magnetic iron oxides during the heating cycle. Although an increase in susceptibility is often apparent after heating to temperatures above $400^{\circ} \mathrm{C}$, the increase is particularly marked for samples from Core 13 (Fig. 17).

\section{Microscopy-Observations}

In order to directly observe the magnetic mineralogy, magnetic extracts from Core 3 and Core 13 were studied using the scanning electron microscope. Titanomagnetite was the dominant magnetic mineral in both extracts. Identification was based on crystal form, and elemental determinations from the EDS. The extract from Core 13 differed from that from Core 3 in several respects. Firstly, $40 \%$ more magnetic extract was recovered from Core 3 than from Core 13, although the same initial sample weight was used. Secondly, the Core 13 extract was devoid of magnetite grains smaller than several micrometers in diameter. Thirdly, whereas the Core 3 extract was characterized by pristine titanomagnetite grains, the Core 13 extract was composed of abundant pitted titanomagnetites which sometimes had secondary sulfide overgrowths (Fig. 18). The X-ray fluorescence indicated that the iron sulfide contained significant amounts of titanium. This observation and the distorted crystal form of the iron sulfides indicates that the reduction of the magnetite is occurring "in situ" without migration and reprecipitation of reduced iron.

\section{Oxidation State of Iron-Observations}

The ferrous/ferric iron ratio of the bulk sediment increases down core (Fig. 19). This trend also argues for progressive "in situ" sulfide formation with insignificant migration of reduced iron.

\section{Interpretation}

The magnetic, microscopic, and chemical observations are consistent with progressive downcore dissolution of primary detrital titanomagnetites in the Plio-Pleistocene sediments at Site 653. The microscopic observations (Fig. 18) and the observed jumps in susceptibility during heating (Fig. 17) strongly suggest that iron sulfide is being formed downcore. A rather abrupt decrease in NRM intensity (Fig. 11), SIRM intensity (Fig. 12), and ARM intensity (Fig. 13) occurs close to 50 mbsf; this may coincide with the level at which much of the remanence-carrying fine-grained magnetite fraction disappears. The MDF appears to increase downward throughout the core (Fig. 14), and the ferrous/ferric iron ratio has a similar trend (Fig. 19). The increasing ferrous/ferric iron ratio reflects the replacement of magnetite by iron sulfide. We suspect that the increasing MDF downcore is due to a progressive etching resulting in a decrease in the 
$10-1,59$

( $150 c-600 c)$

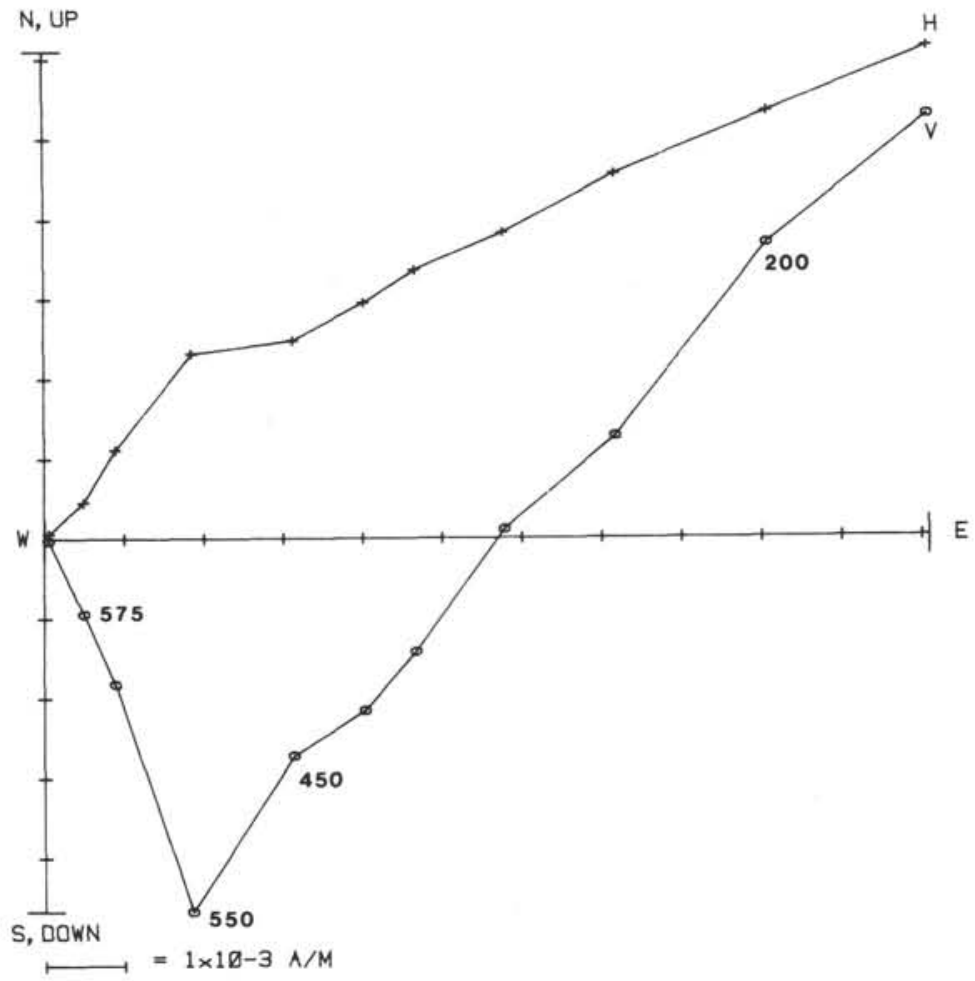

12-1, 7

( NRM - 6øøC)

N, UP

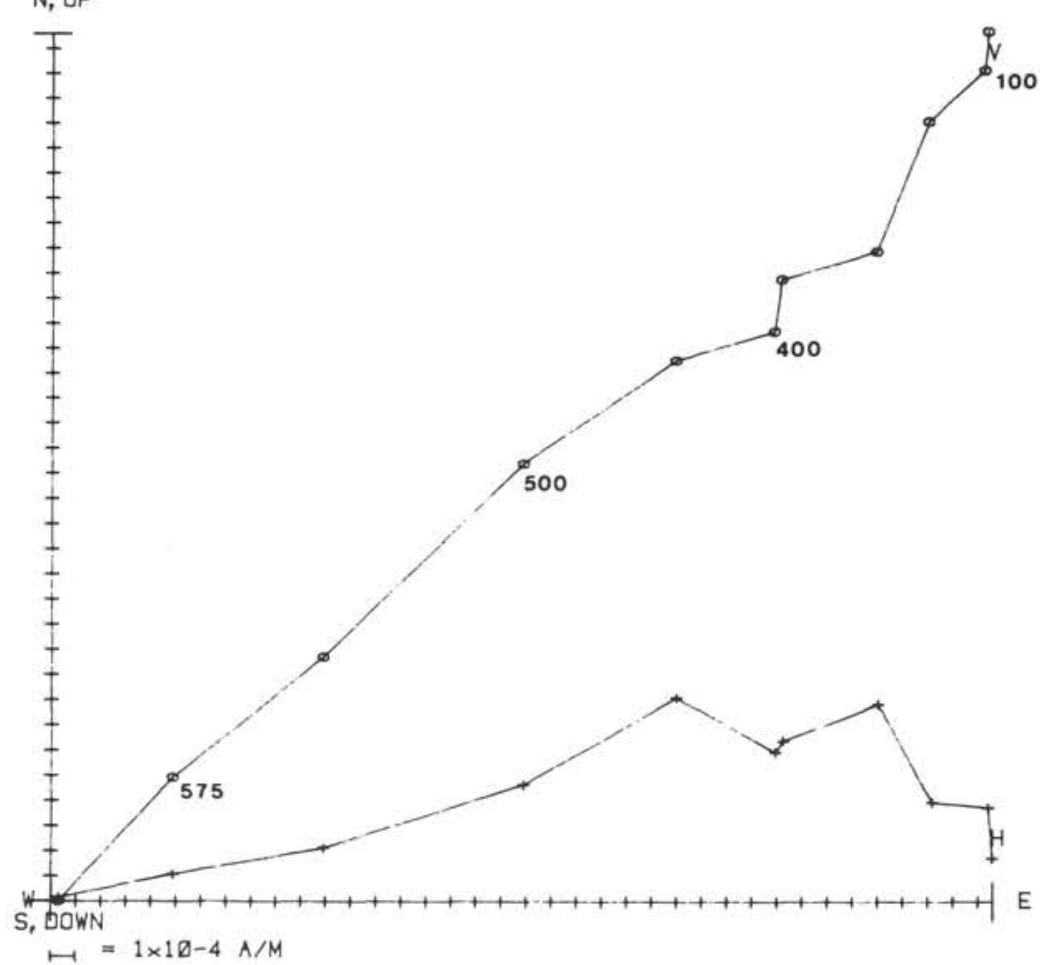

$21-1,24$

( NRM - 6øøC)

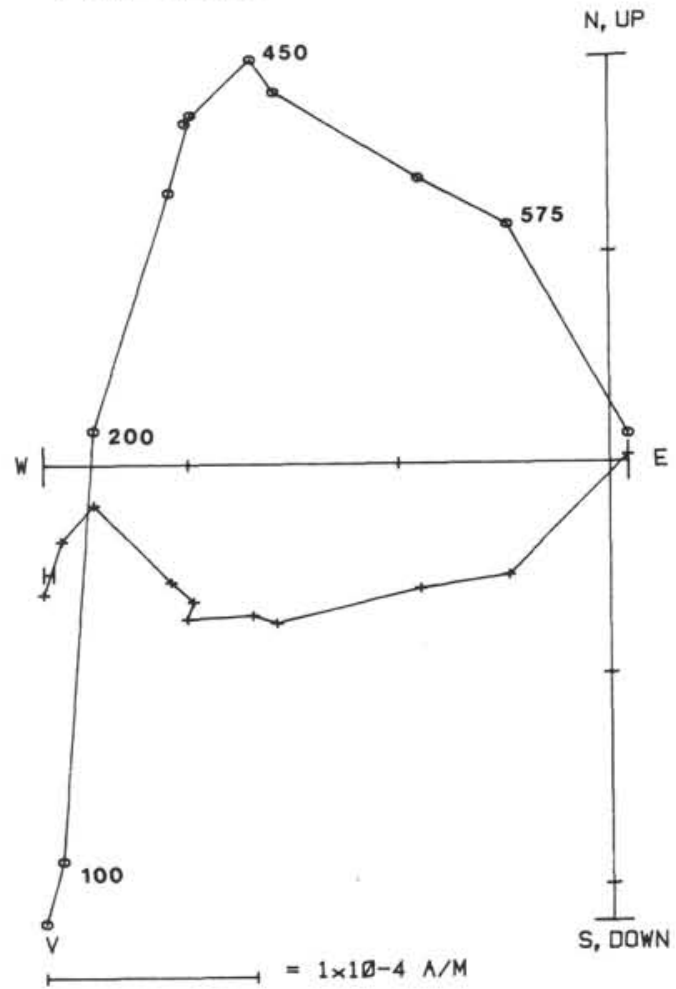

$9-3,86$

( NRM - 6øøC)

$N$, UP

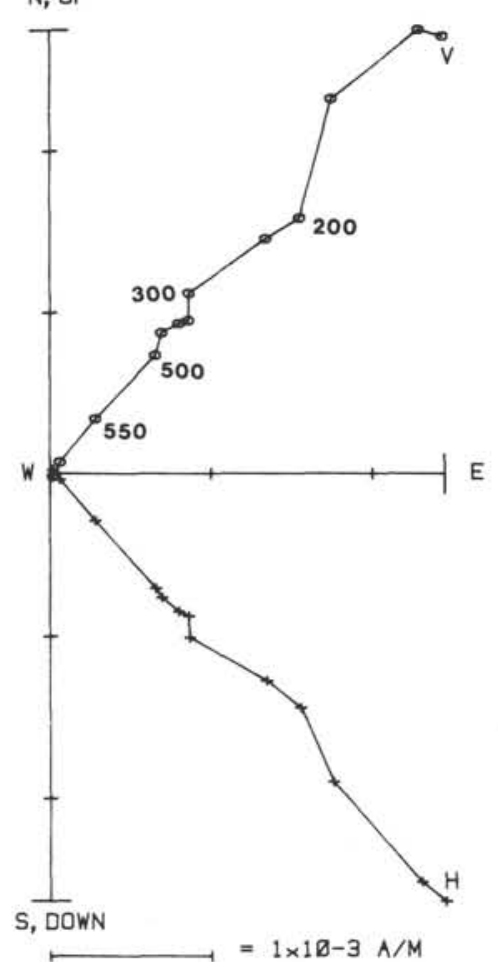

Figure 2. Orthogonal projection of thermal demagnetization data from the Plio-Pleistocene section at Site 654. Crosses and circles represent the projection of the magnetization vector end-point on the horizontal and vertical plane, respectively. The demagnetization temperature range is given in degrees Celsius, and temperatures corresponding to certain points are indicated. 
$32-1,29$

( NRM - 99mT)

$\mathrm{N}$, UP

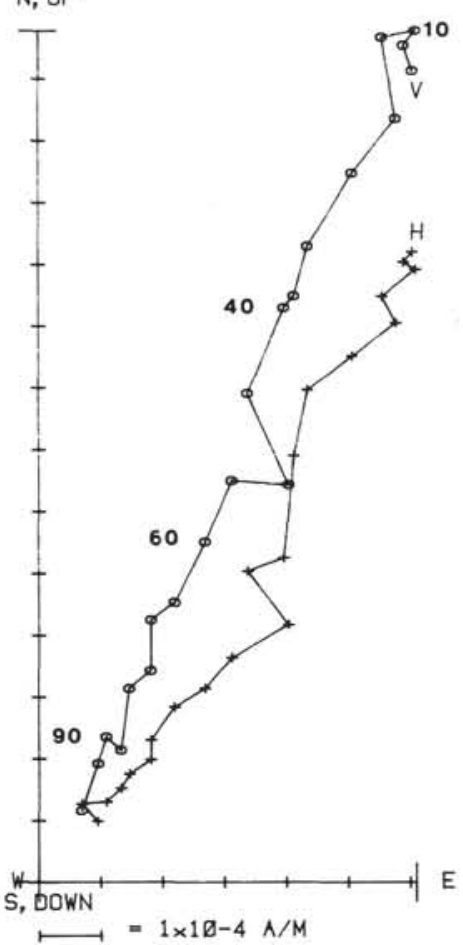

$31-1,145$

$(50-99 \mathrm{mI})$

$\mathrm{N}$, UP

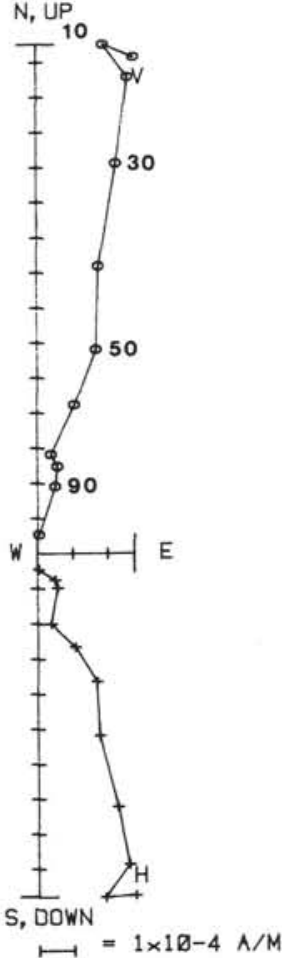

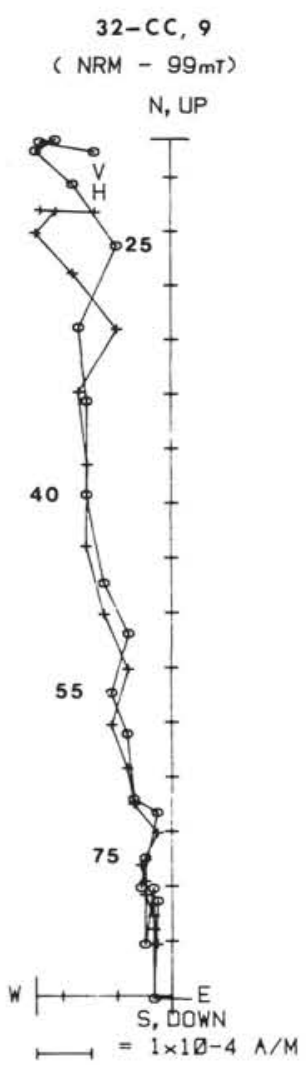

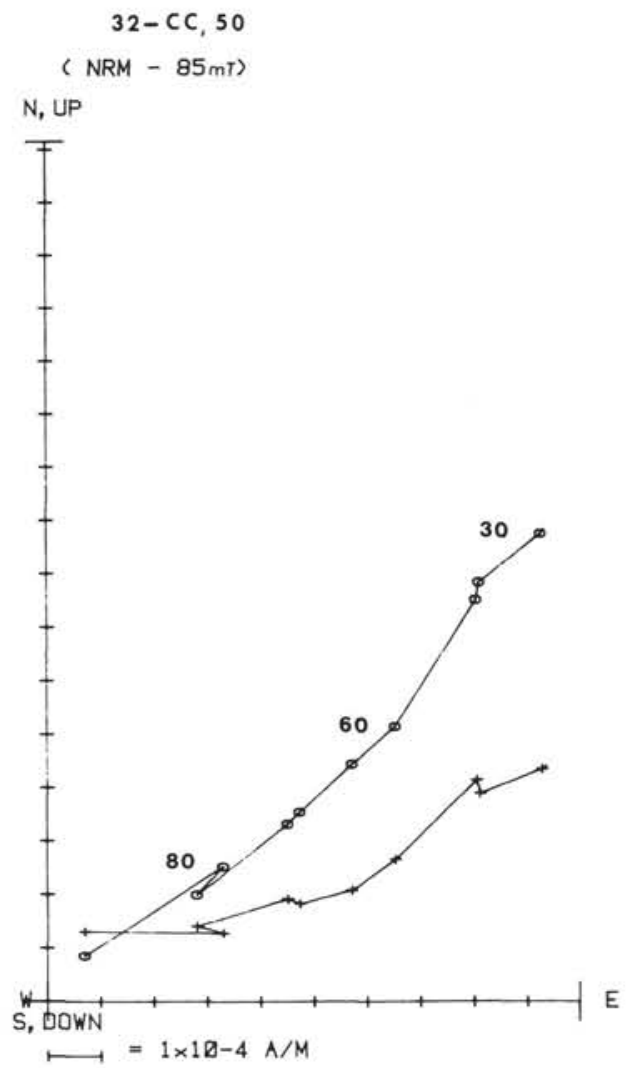

Figure 3. Orthogonal projection of alternating field demagnetization of balatino-type gypsum samples from Site 654. The ranges of peak demagnetizing fields are given in $\mathrm{mT}$, and the peak fields associated with certain points are shown. Other symbols as for Figure 2. 


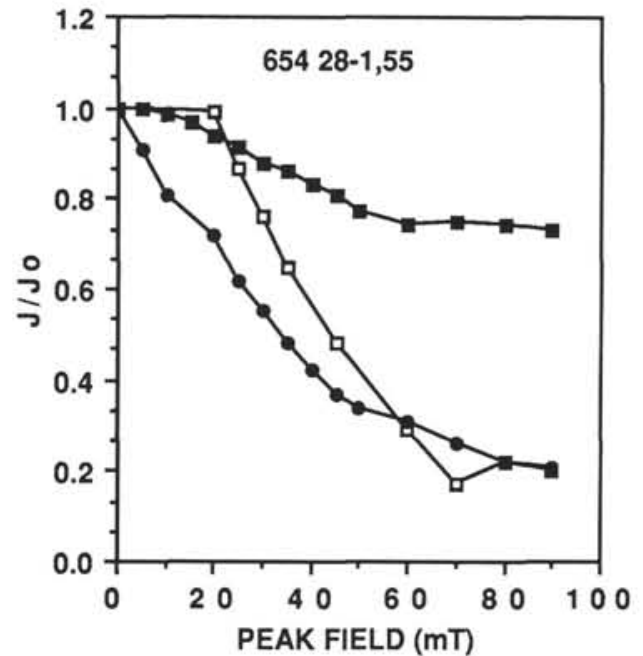

Figure 4. Intensities of NRM (open squares), ARM (solid squares), and SIRM (solid circles) as a function of peak alternating field during $\mathrm{AF}$ demagnetization of a sample of balatino-type gypsum from Site 654 .

effective grain size of the magnetite as alteration proceeds, rather than any contribution to the remanence from the iron sulfide. This conclusion is based on the fact that we see no evidence for a sulfide remanence carrier in the blocking temperature spectrum during the thermal demagnetization of the NRM (Fig. 8). Karlin and Levi (1985) have interpreted increasing downcore coercivity in Pacific hemipelagic sediments by postulating an analogous progressive decrease in effective magnetite grain size.

\section{CONCLUSIONS}

The emphasis on Site 653 as the principal site for the stratigraphic objectives of Leg 107 requires that we determine why this site did not yield a magnetostratigraphy. A combination of magnetic, microscopic, and chemical methods has shown that the detrital titanomagnetites at this site have undergone progressive downcore dissolution in reducing diagenetic conditions. This dissolution has destroyed the fine-grained magnetite which we postulate carries the characteristic remanence at other Leg 107 sites. The lower coercivity coarser-grained magnetite carries a secondary magnetization which becomes progressively hardened as etching reduces its effective grain size. Iron sulfides coat pitted titanomagnetite grains in the lower part of the core. The sulfides do not appear to contribute to the magnetic remanence.

Reduction of magnetite to iron sulfide during marine diagenesis has been observed in a variety of sedimentary environments characterized by high organic content (Kobayashi and Nomura, 1972; Suttill et al., 1982; Karlin and Levi, 1985; Canfield and Berner, 1987). Canfield and Berner (1987) have demonstrated that the rate of magnetite dissolution is controlled by the surface area of the magnetite grains and the concentration of dissolved sulfide. The concentration of dissolved sulfide is controlled in turn by the availability of sulfate and of sulfate-reducing bacteria. It is unlikely that the availability of sulfate varied between Sites 653 and 654 . The Plio-Pleistocene sediments at both sites are underlain by Messinian evaporites which may have provided a source for sulfate in addition to the seawater source. The critical difference between the diagenetic environment at the two sites is likely to be the concentration of organic matter. The concentration of organic matter that can be metabolized by sulfate-reducing bacteria is the primary control on the availability of dissolved sulfide in environments where there is abundant sulfate in the pore waters. As the total thicknesses and sedimentation rates of the Plio-Pleistocene sequences at Sites 654 and

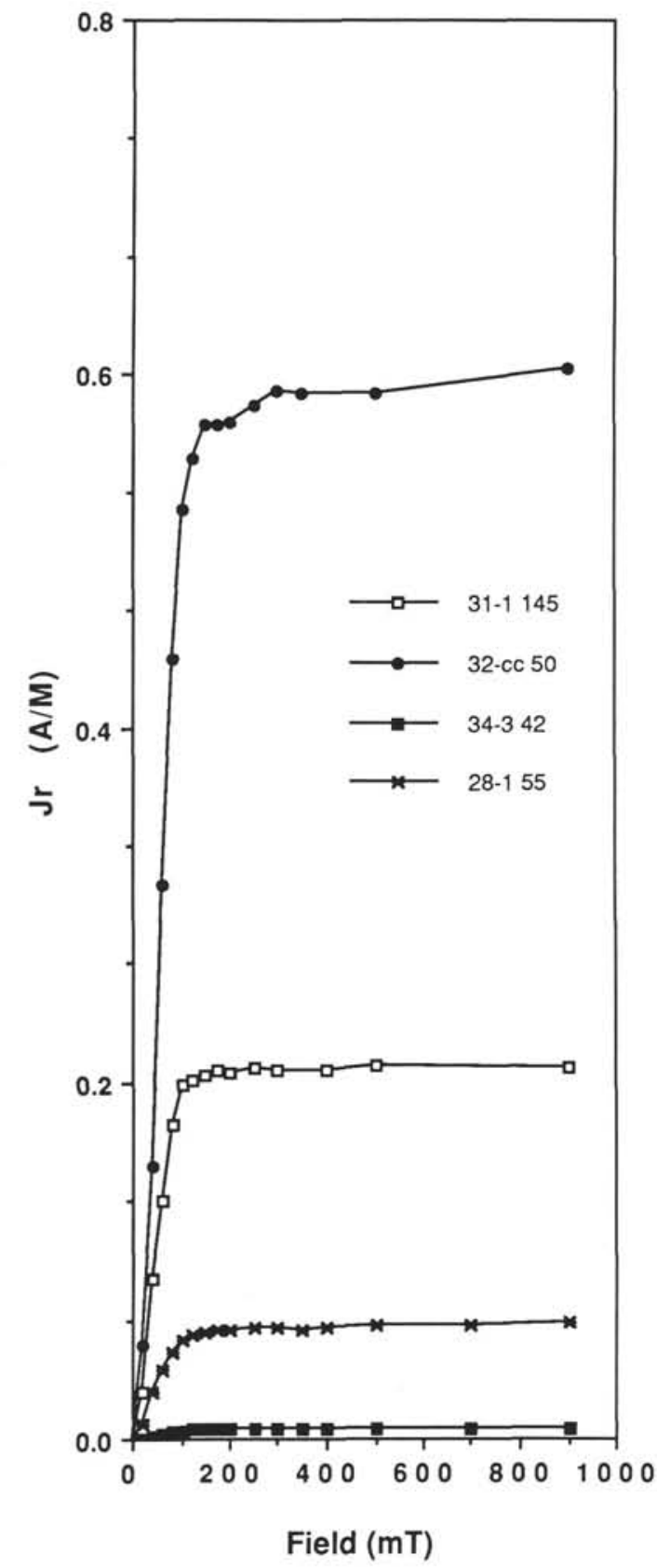

Figure 5. Acquisition of IRM as a function of magnetizing field for samples of balatino-type gypsum from Site 654 .

653 are similar, sedimentation rate is probably not controlling differences in preservation of organic matter at the two sites. We suggest that bottom water conditions at Site 653 , which is located in the deeper part of the Cornaglia Basin (Fig. 1) enhanced the accumulation and burial of organic matter relative to the bottom water conditions at other Leg 107 sites, such as Site 654 .

At Sites $650,651,652$, and 654 , the dissolution of magnetite does not result in the total degradation of the primary magnetization. It is usually possible to resolve a high blocking temperature component which defines a polarity stratigraphy (see Channell et al., this volume). However, the magnetostratigraphies at Sites 651,652 , and 654 are severely compromised by core disturbance and poor recovery as a result of rotary drilling. The Miocene sediments recovered at Site 654 and Site 652 yielded magne- 


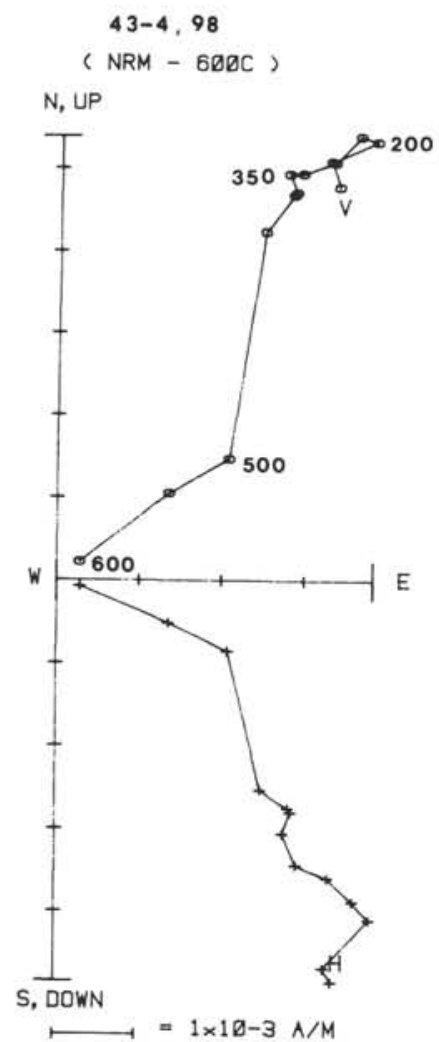

$43-5,144$

( NRM - 6ø0C)

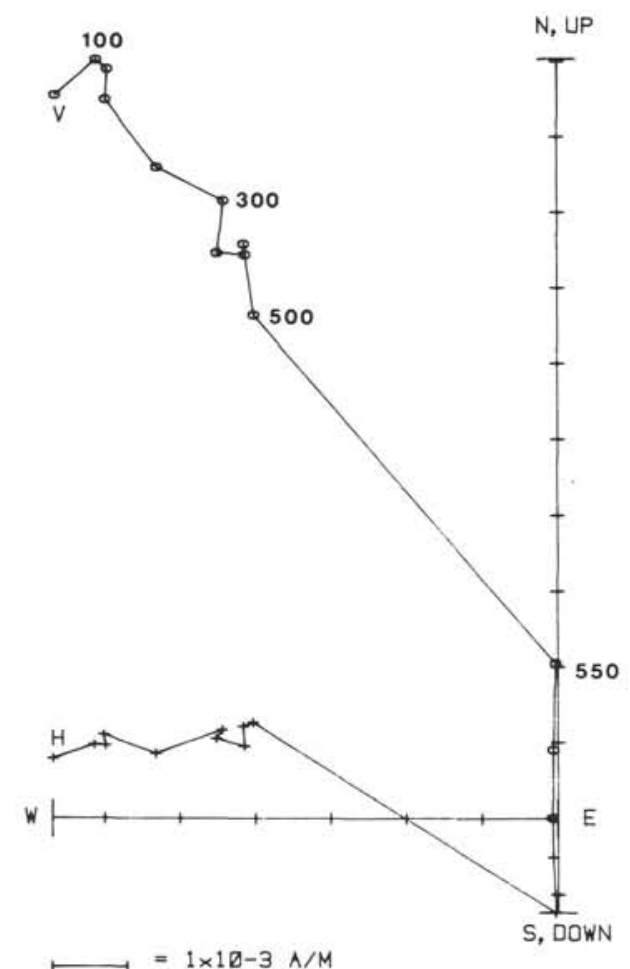

$43-3,84$

( NRM - 6ø0C)

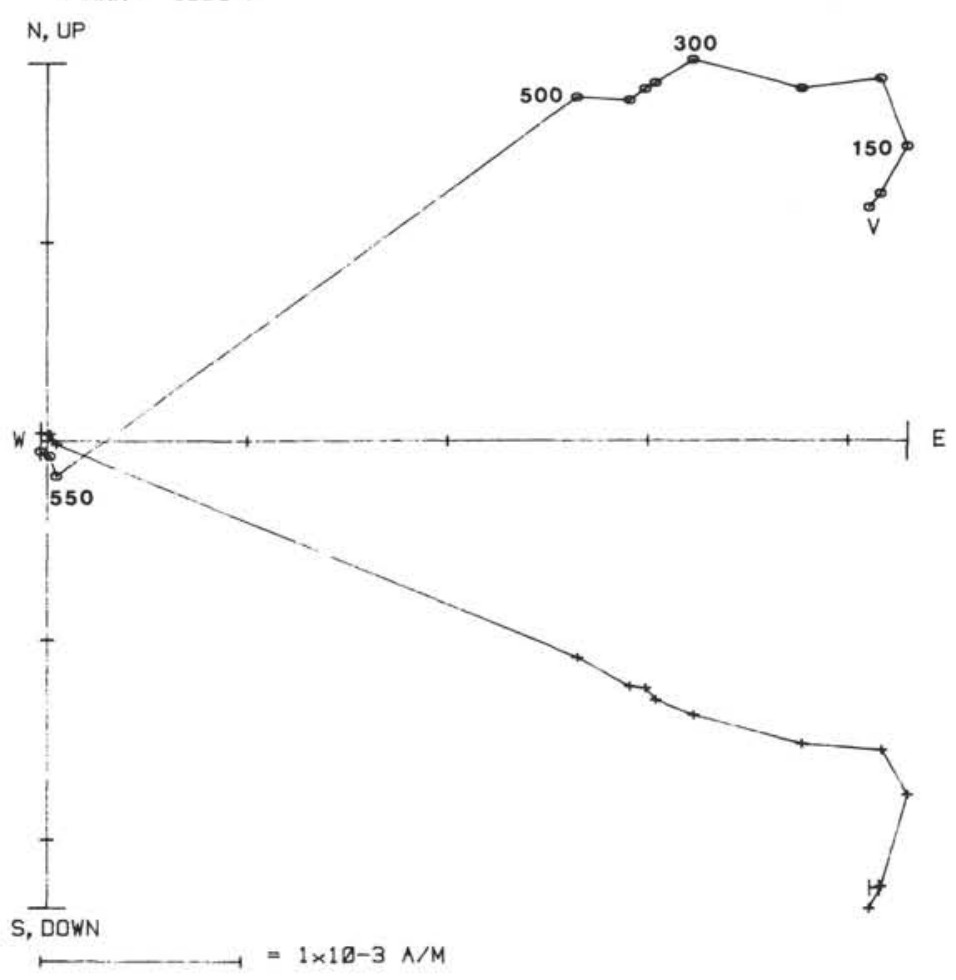

Figure 6. Orthogonal projection of thermal demagnetization of samples from the Tortonian sediments at Site 654. Symbols as for Figure 2. 
J.E.T. CHANNELL, T. HAWTHORNE, M. TORII
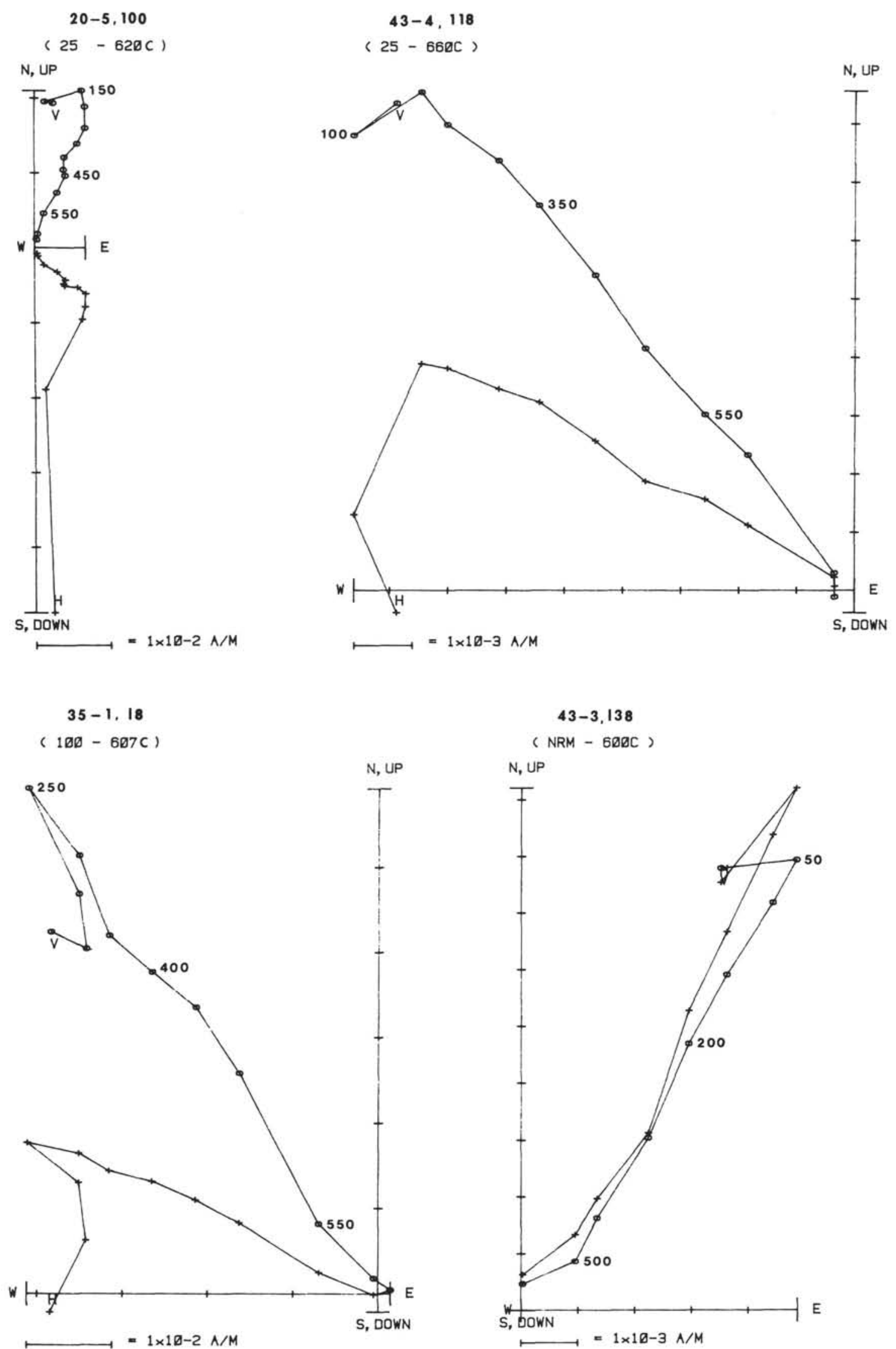

Figure 7. Orthogonal projection of thermal demagnetization of samples from the pre-Pliocene sediments at Site 652. Symbols as for Figure 2. 
31-1, 81

( NRM - 6ø0C)

N, UP

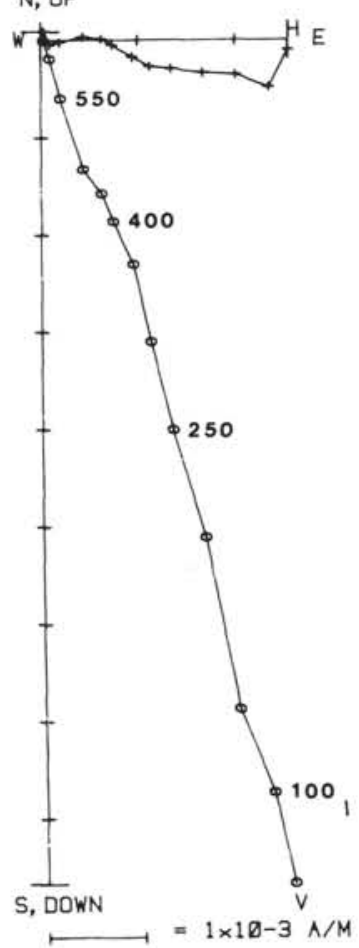

$10-1,107$

( $150 c-600 c)$

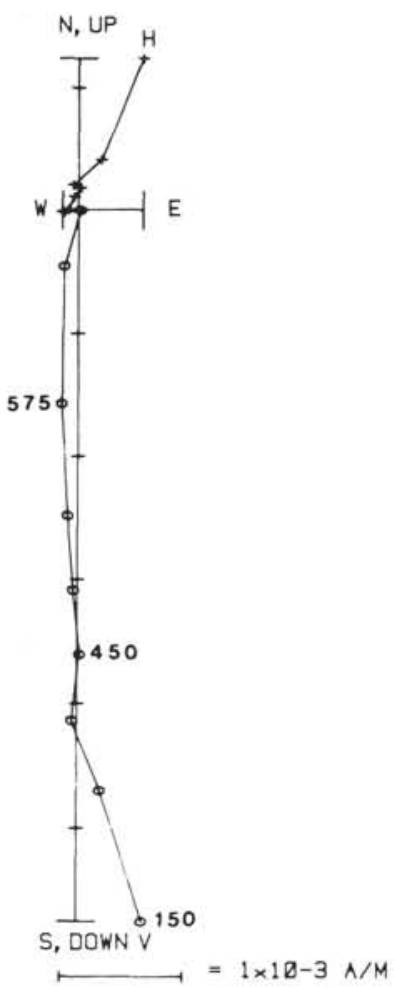

$7-4,130$

( NRM - 6פ0C)

${ }_{\mathrm{H}} \mathrm{N}$, UP

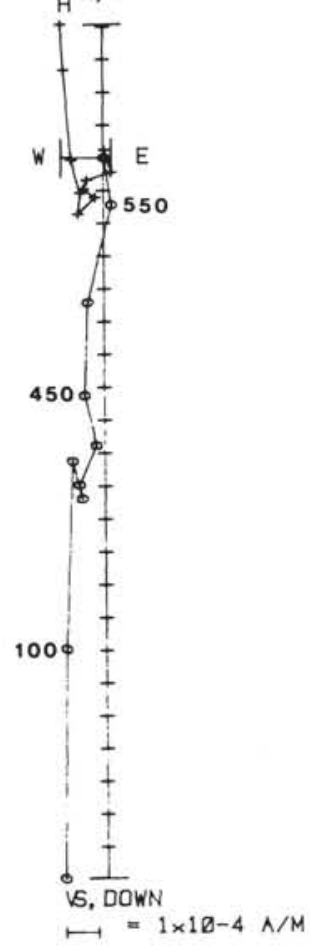

$16-4,131$

( NRM - 600C)

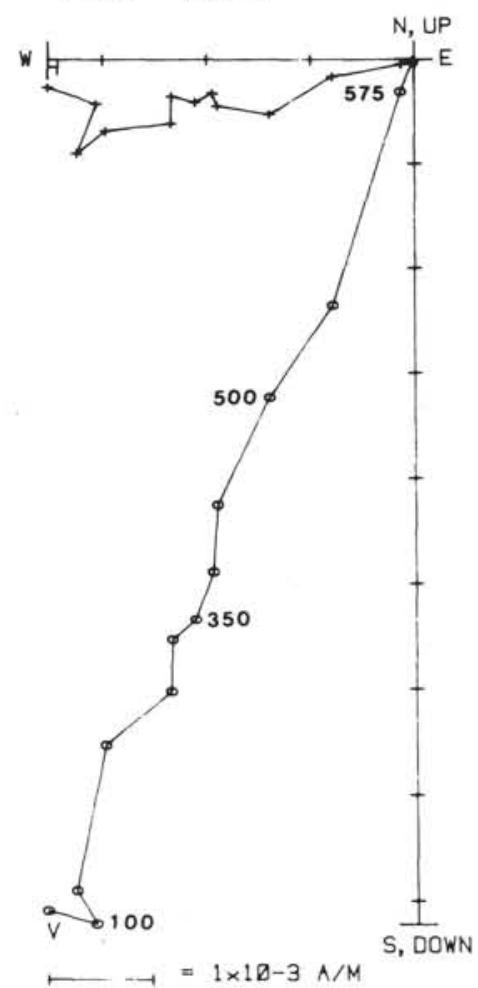

$9-2,10$

( NRM - 6פøC)

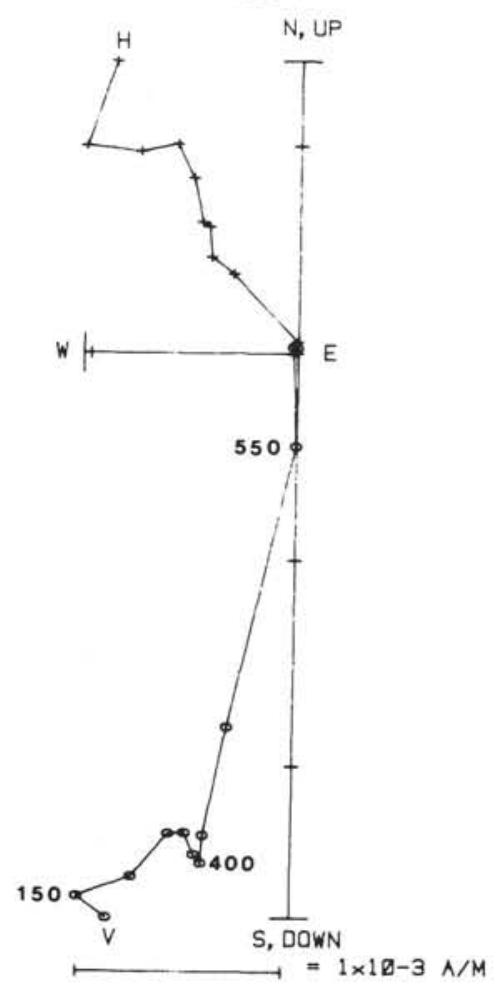

$18-5,83$

( NRM - 600C)

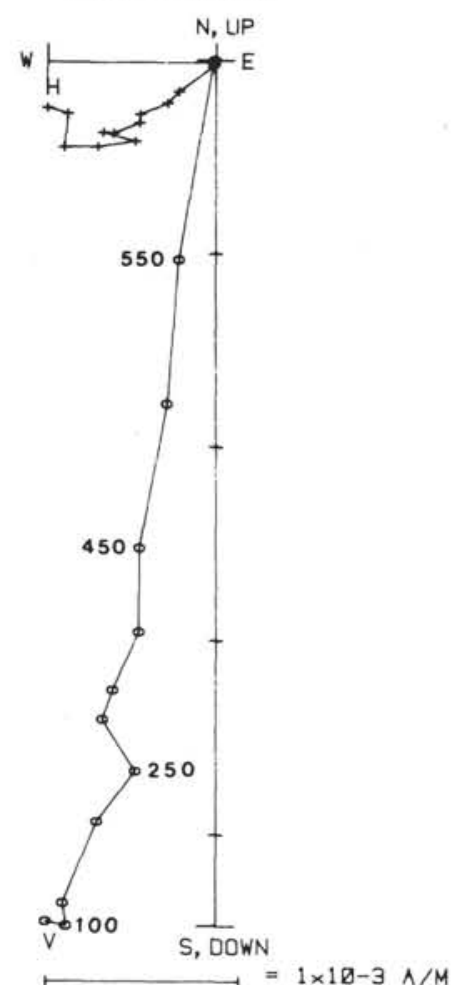

Figure 8. Orthogonal projection of thermal demagnetization of samples from Plio-Pleistocene sediment at Site 653. Symbols as for Figure 2. 


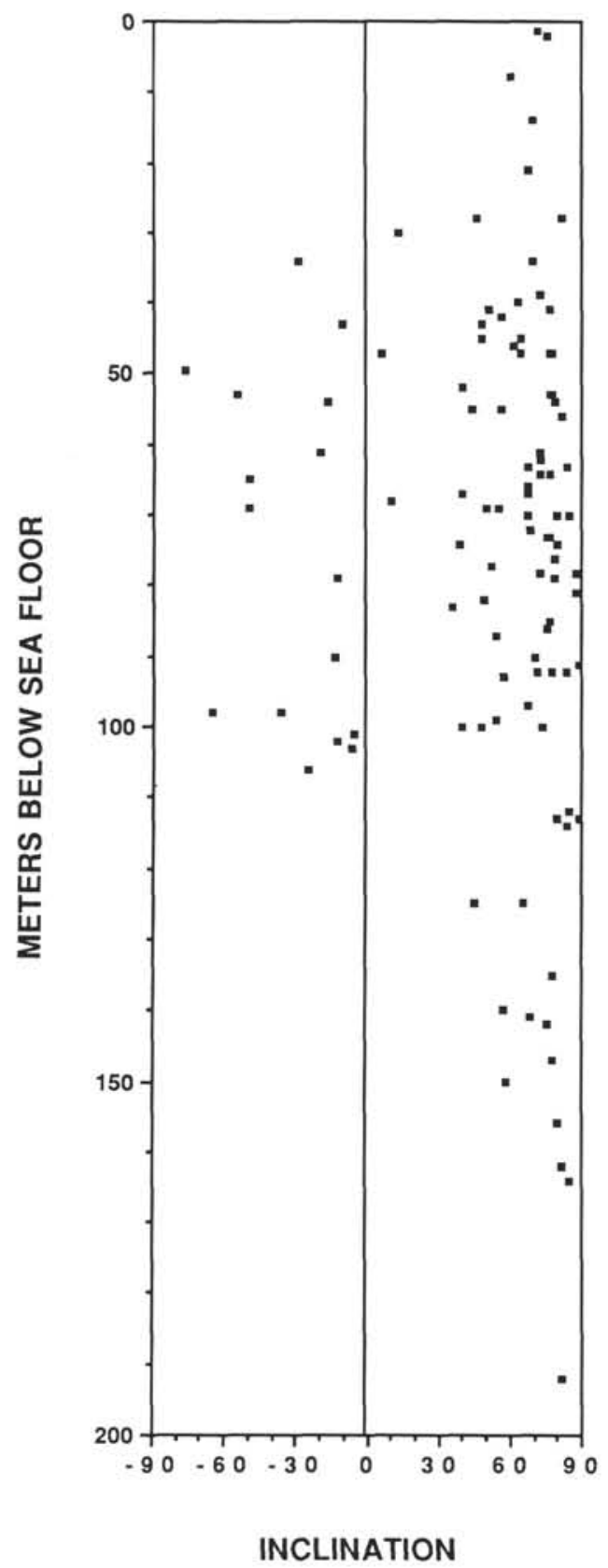

Figure 9. Inclination of the high blocking temperature magnetization component plotted against depth for Hole 653A.

tostratigraphies which are again compromised by poor recovery, but they provide critical age information. The balatino-type gypsum at Site 654 gave a well-defined magnetization component carried by titanomagnetite which we consider to be primary in origin.

In view of the importance of obtaining a good quality PlioPleistocene magnetic stratigraphy from Leg 107, the choice of Site 653 as the principal site with stratigraphic objectives was extremely unfortunate. This is the only site where alteration of detrital titanomagnetite has destroyed the primary magnetization. Efforts at constructing a magnetic stratigraphy at Site 652 and 654 have been severely hampered by poor recovery and core disturbance due to rotary drilling.

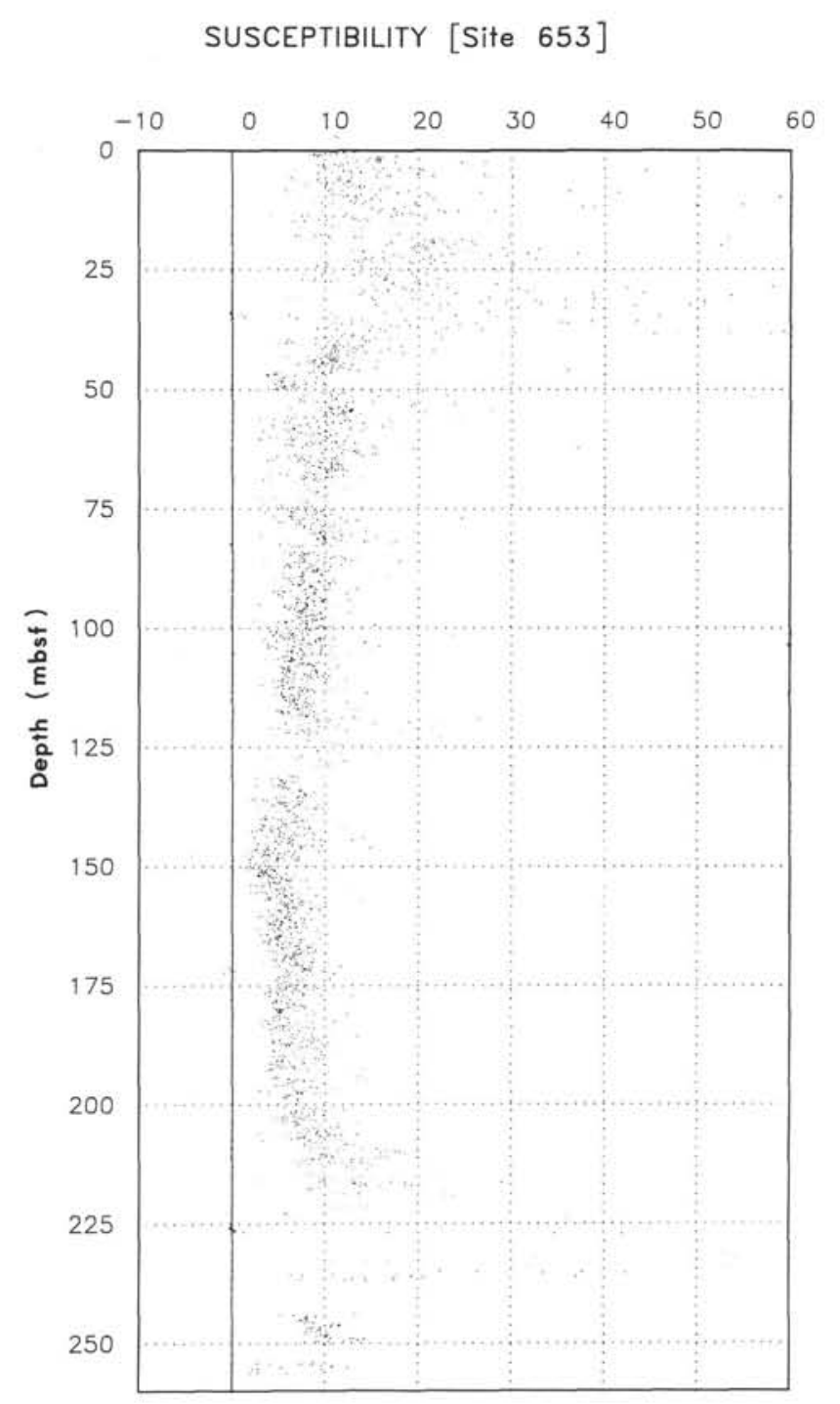

Figure 10. Susceptibility plotted against depth for both Hole 653A and Hole 653B.

\section{ACKNOWLEDGMENTS}

We thank Raymond Berggeran and his research team in the Department of Medical Chemistry (UF) for help and advice. We acknowledge financial support from Texas A\&M Research Foundation/USSP.

\section{REFERENCES}

Bloemendal, J., Lamb, B., and King, J., 1988. Paleoenvironmental implications of rock magnetic properties of Late Quaternary sediment cores from the eastern equatorial Atlantic. Paleoceanography, 3:6188.

Canfield, D. E., and Berner, R. A., 1987. Dissolution and pyritization of magnetite in anoxic marine sediments. Geochim. Cosmochim. Acta., 51:645-659.

Cox, A., 1982. Magnetostratigraphic time scale, In Harland, W. B., et al., (Eds.) A Geologic Time Scale, Cambridge (Cambridge Univ. Press), $128 \mathrm{p}$.

Doh, S., King, J. W., and Leinen, M., 1988. A rock-magnetic study of giant piston core LL44-GPC 3 from the central north Pacific and its paleoceanographic implications. Paleoceanography, 3:89-112.

Dunlop, D. J., 1972. Magnetic mineralogy of unheated and heated red sediments by coercivity spectrum analysis. Geophys. J. Roy. Astr. Soc., 27:37-55. 
Fritz, S. F., and Popp, R. K., 1985. A single-dissolution technique for determining $\mathrm{FeO}$ and $\mathrm{Fe}_{2} \mathrm{O}_{3}$ in rock and mineral samples. Am. Mineral., 70:961-968.

Johnson, H. P., Lowrie, W., and Kent, D. V., 1975. Stability of anhysteretic remanent magnetization in fine and coarse magnetite and maghemite particles. Geophys. J. Roy. Astr. Soc., 41:1-10.

Karlin, R., and Levi, S., 1985. Geochemical and sedimentological control of the magnetic properties of hemipelagic sediments. J. Geophys. Res., 90:10373-10392.

King, J., Banerjee, S. K., Marvin, J., and Ozdemir, O., 1982. A comparison of different magnetic methods for determining the relative grain size of magnetite in natural materials: some results from lake sediments. Earth Planet. Sci. Lett., 59:404-419.

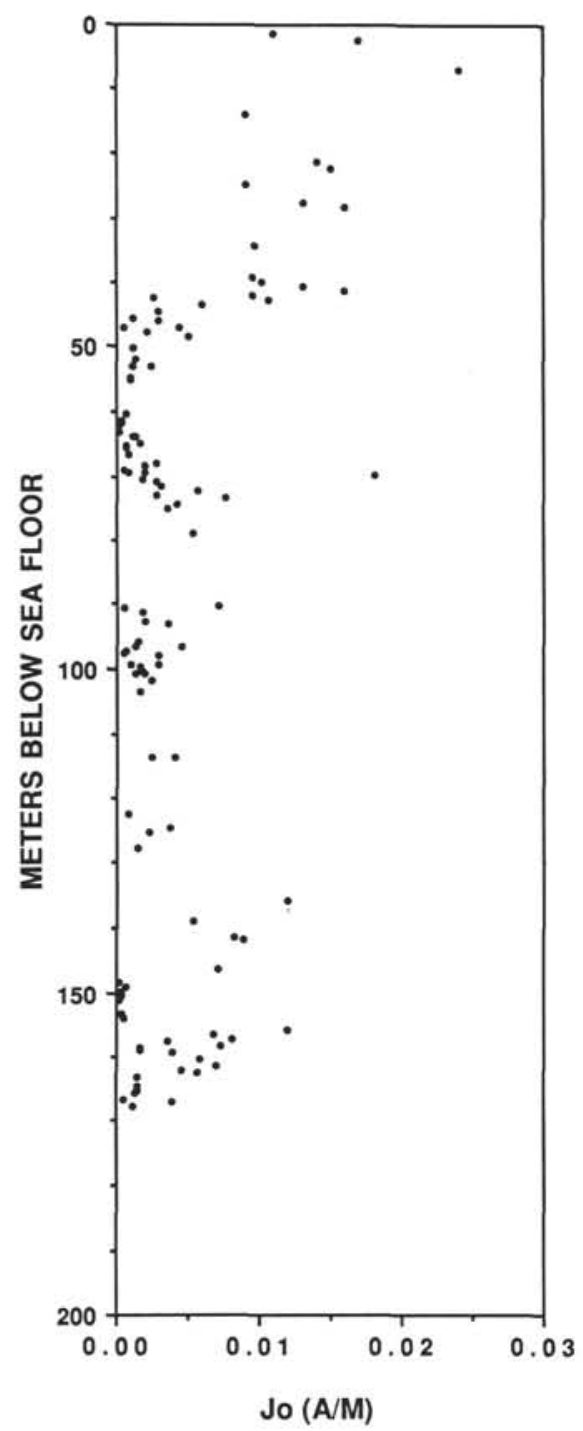

Figure 11. Natural remanent magnetization (NRM) intensity plotted against depth at Hole 653A.
Kobayashi, K., and Nomura, M., 1972. Iron sulfides in the sediment cores from the Sea of Japan and their geophysical implications. Earth Planet. Sci. Lett., 16:200-208.

Lowrie, W., and Fuller, M., 1971. On the alternating field demagnetization characteristics of multidomain thermoremanent magnetization in magnetite. J. Geophys. Res., 76:6339-6349.

Suttill, R. J., Turner, P., and Vaughn, D. J., 1982. The geochemistry of iron in recent tidal flat sediments of the Wash area, England: a mineralogical, mossbauer and magnetic study. Geochim. Cosmochim. Acta., 46:205-217.

Date of initial receipt: 5 January 1988

Date of acceptance: 2 December 1988

Ms 107B-166

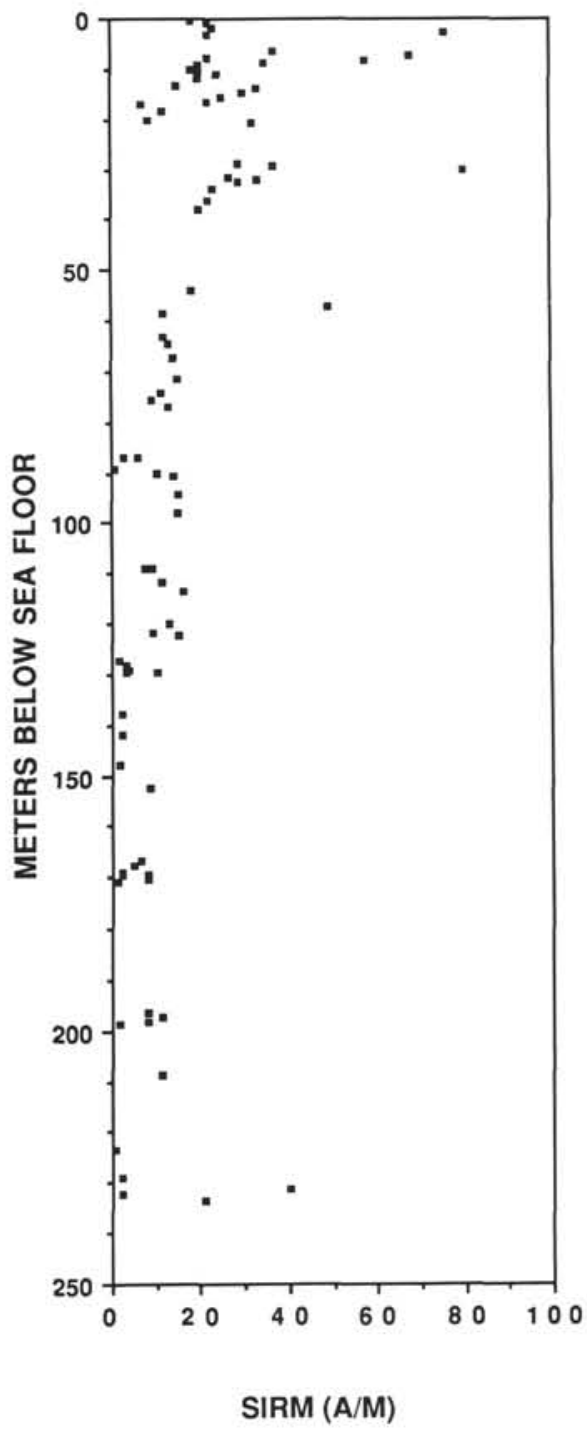

Figure 12. Saturation isothermal remanent magnetization (SIRM) plotted against depth at Hole 653A. 


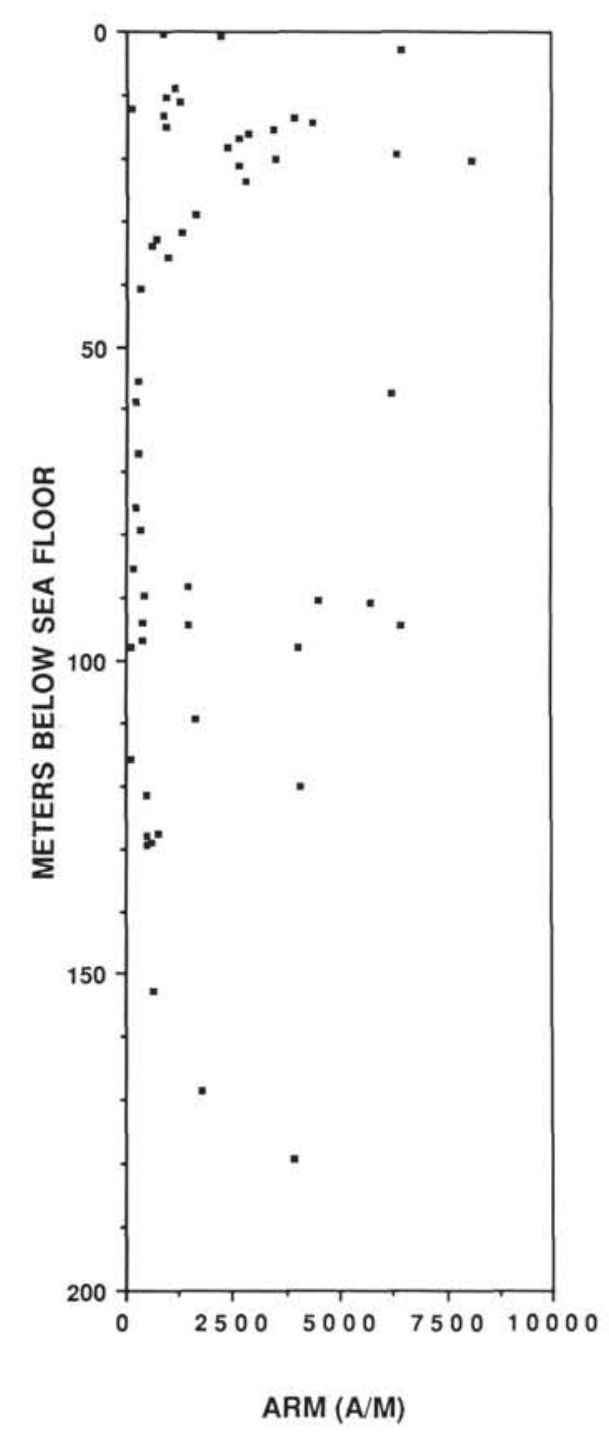

Figure 13. Anhysteretic remanent magnetization (ARM) plotted against depth at Hole 653A.

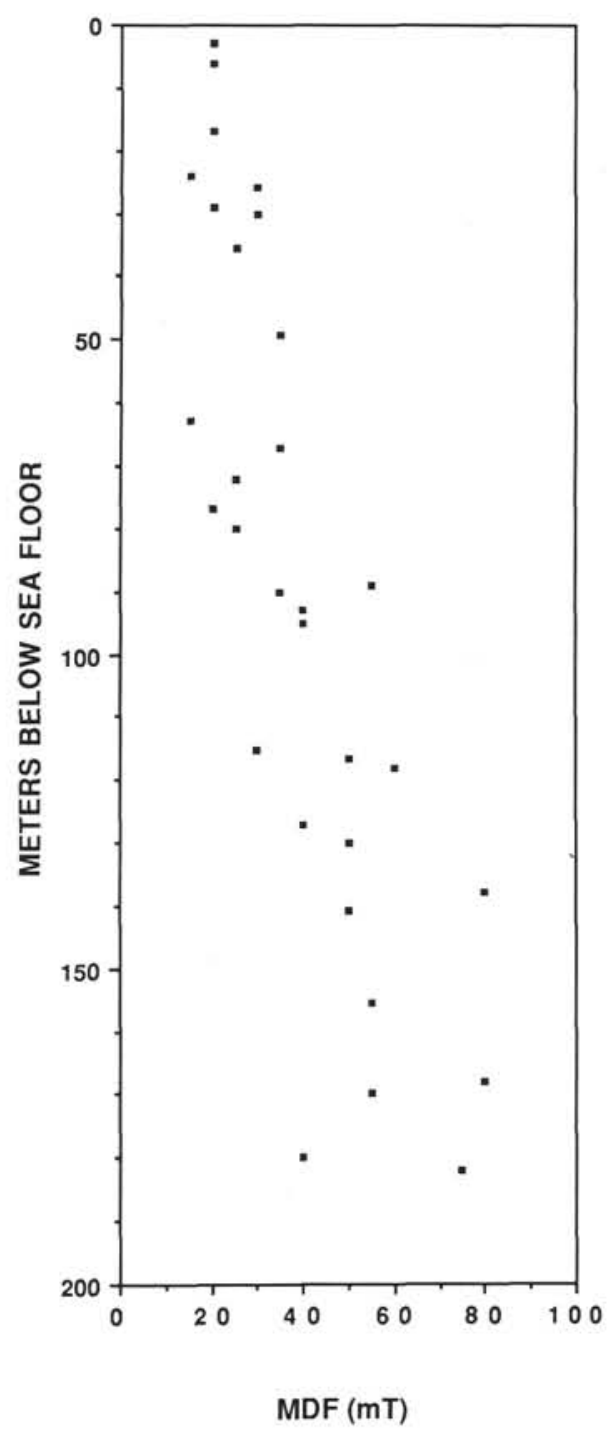

Figure 14. Median destructive field (MDF) plotted against depth at Hole 653A. 


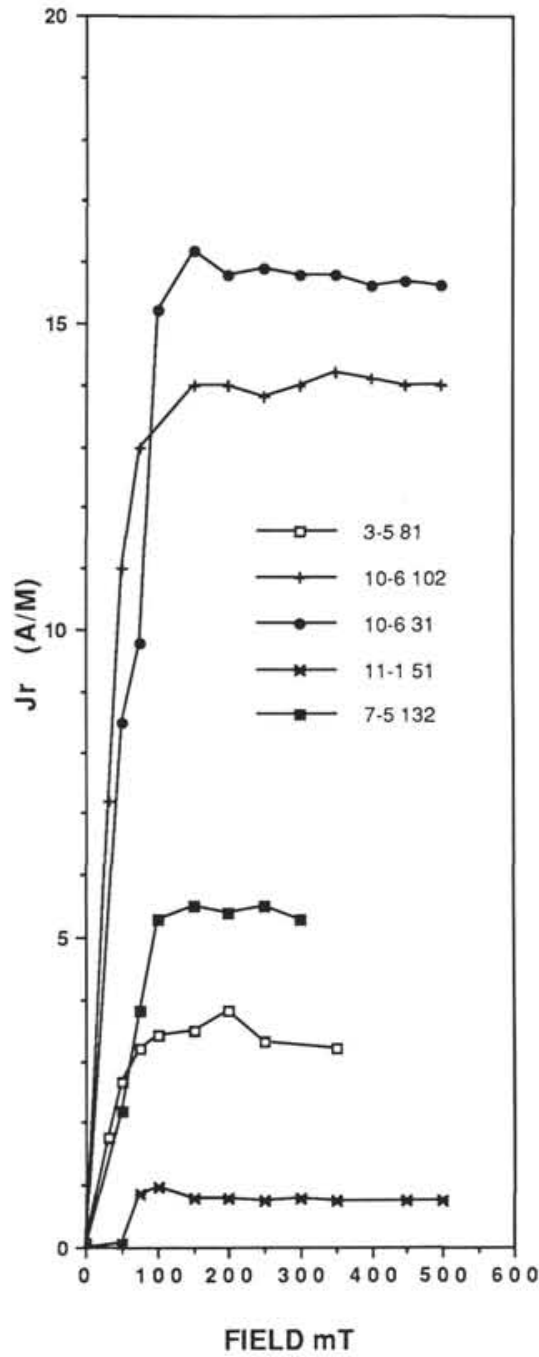

Figure 15. Acquisition of isothermal remanent magnetization (IRM) for several samples from the upper part of Hole 653A. 

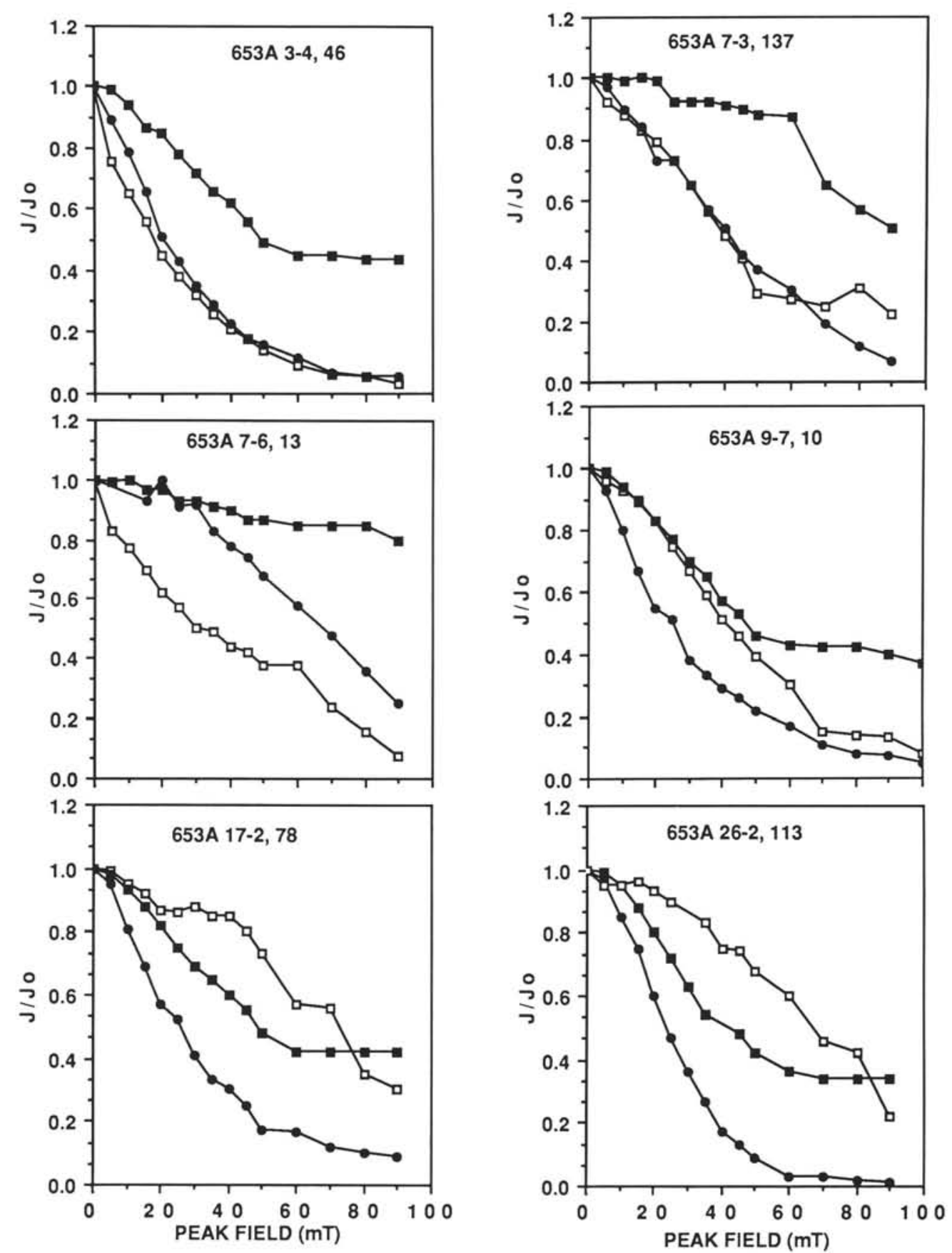

Figure 16. Intensity of NRM (open squares), ARM (solid squares), and SIRM (solid circles) plotted against peak alternating field, during progressive alternating field demagnetization of samples from Hole 653A. 


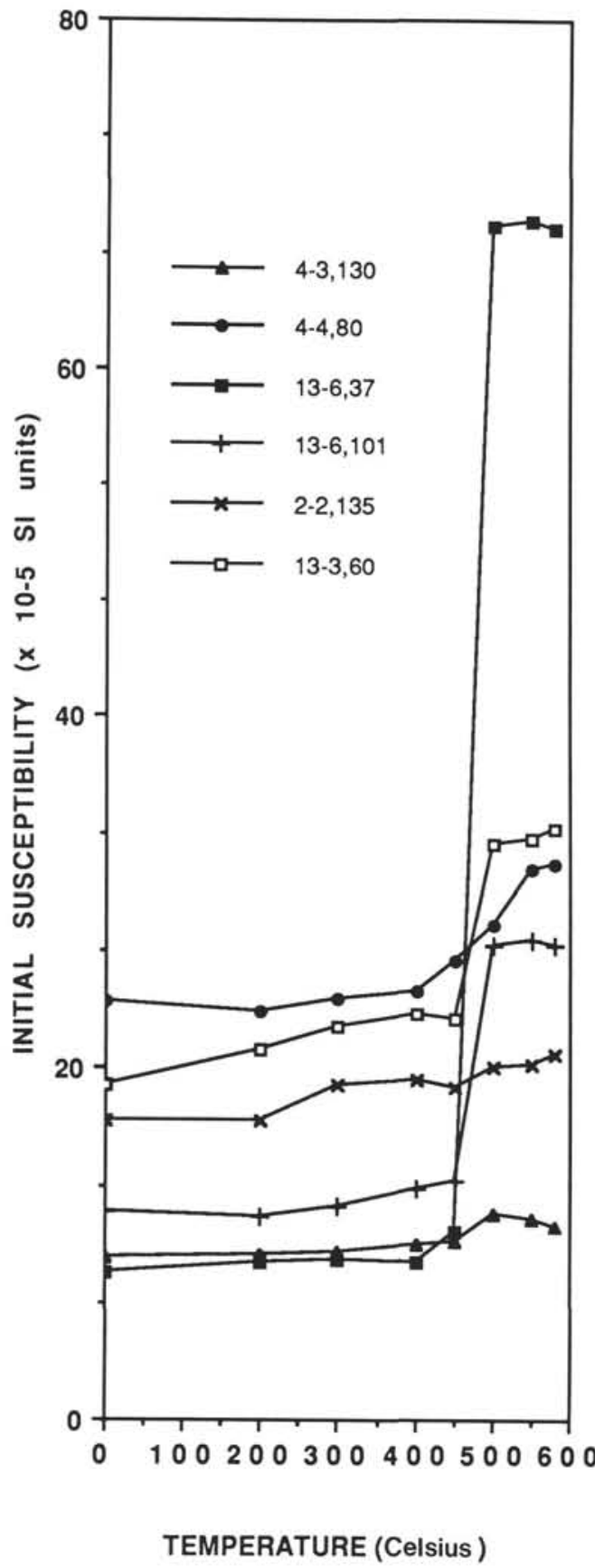

Figure 17. Initial susceptibility after heating for various samples from Hole $653 \mathrm{~A}$.
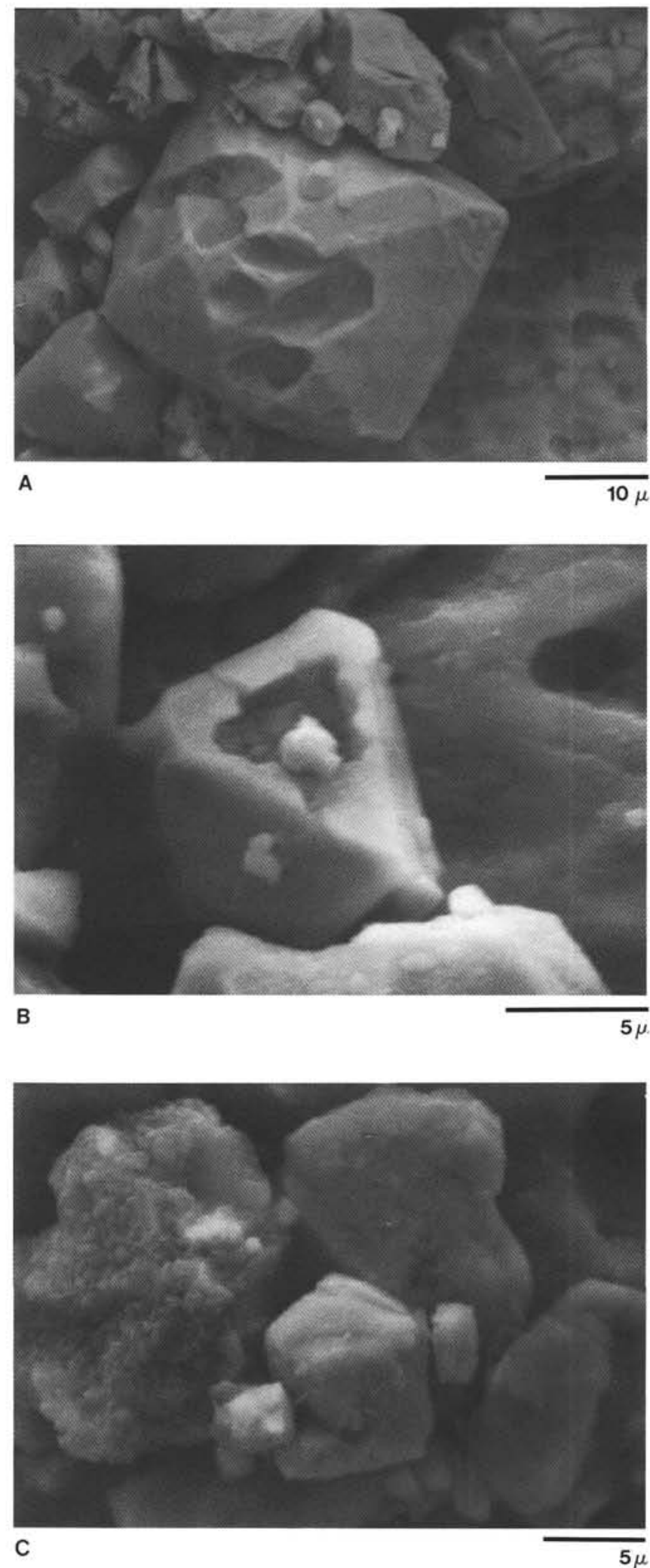

Figure 18. A. Photomicrograph of a pitted titanomagnetite dipyramid from Hole $653 \mathrm{~A}$, Core 13. Scale bar corresponds to $10 \mu \mathrm{m}$. B. Photomicrograph of a pitted titanomagnetite dipyramid from Hole $653 \mathrm{~A}$, Core 13 , which contains fine-grained iron sulfides within the void. Scale bar corresponds to $5 \mu \mathrm{m}$. C. Photomicrograph of a iron titanium sulfide (center) with abnormal crystal form, and a large titanomagnetite (upper left) coated with fine-grained iron sulfides, from Hole 653A, Core 13. Scale bar corresponds to $5 \mu \mathrm{m}$. 


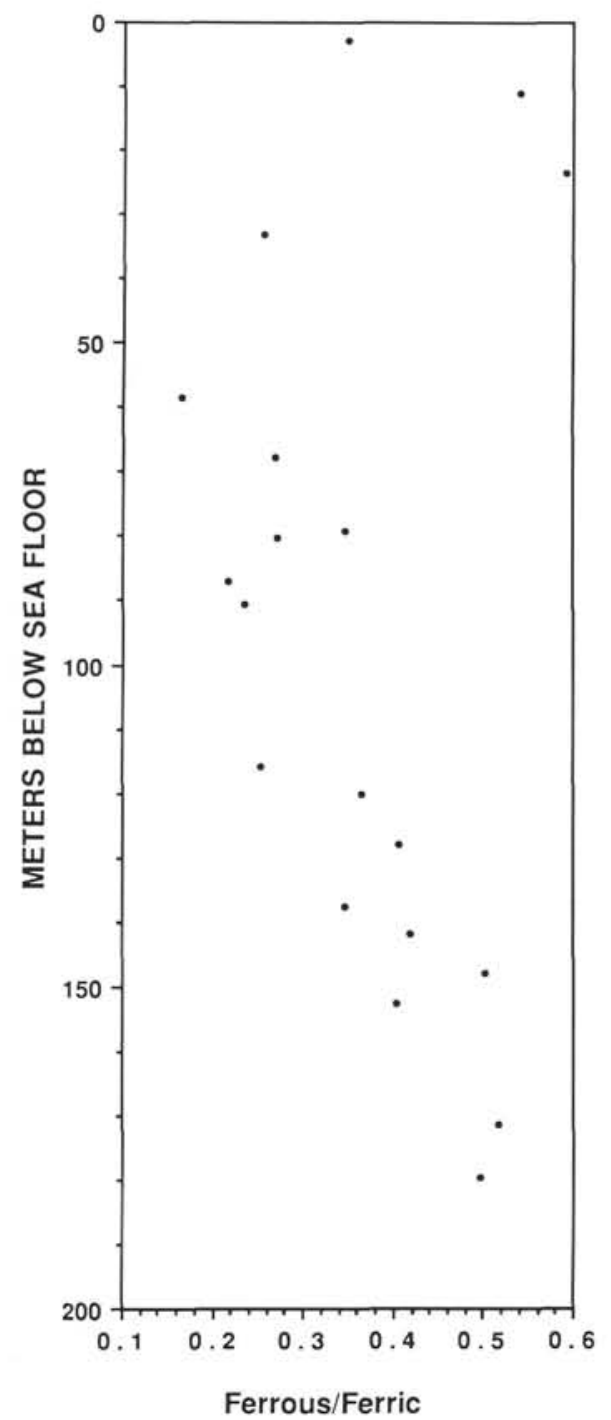

Figure 19. Ferrous/ferric iron ratio plotted against depth for Hole $653 \mathrm{~A}$. 